\title{
Clinical Study \\ Identification of Personal Factors in Motor Neurone Disease: A Pilot Study
}

\author{
Louisa Ng and Fary Khan \\ Department of Medicine, Dentistry and Health Sciences, The University of Melbourne, Royal Melbourne Hospital, Poplar Road, \\ Parkville, Melbourne, VIC 3052, Australia \\ Correspondence should be addressed to Louisa Ng, louisa.ng@mh.org.au
}

Received 10 March 2011; Accepted 19 May 2011

Academic Editor: Johannes Bussmann

Copyright ( $\odot 2011$ L. Ng and F. Khan. This is an open access article distributed under the Creative Commons Attribution License, which permits unrestricted use, distribution, and reproduction in any medium, provided the original work is properly cited.

Motor neurone disease (MND) is a devastating condition. This preliminary study aims to identify relevant personal factors affecting the experience of living with MND from the perspective of persons with MND (pwMND) in an Australian cohort. A prospective cross-sectional survey of pwMND $(n=44)$ using an open-ended questionnaire identified personal factors that were categorised thematically. Standardised questionnaires assessed disease severity: depression, anxiety, and stress and coping strategies. Personal factors identified included demographic factors (socioeconomic status), emotional states (depression, anxiety, and fear), coping strategies (problem-based coping and denial), personality, beliefs (religious and personal values), attitudes (of the patient), and others (such as perceived support). An understanding of personal factors by treating clinicians is essential in the provision of optimal care in MND. This study may assist in the development of personal factors within the International Classification of Functioning, Disability, and Health for improved consensus of care and communication amongst treating clinicians.

\section{Introduction}

Motor neurone disease (MND) (amyotrophic lateral sclerosis) is a relatively rare neurodegenerative disorder of the motor system in adults characterized by the loss of motor neurons in the cortex, brain stem, and spinal cord, manifested by upper and lower motor neuron signs and symptoms affecting bulbar, limb, and respiratory muscles. Death usually occurs three-to-five years after onset from respiratory failure, but some may survive for a decade or more [1]. The burden of disease and economic impact of MND upon patients, their caregivers (often family members), and on society is substantial. It often begins long before the actual diagnosis is made and increases with increasing disability and the need for medical equipment and assisted care [2].

With no cure currently available, the challenge in MND is to prolong independence, prevent complications, and optimise quality of life (QoL). This is best met by a multidisciplinary team with a focus on symptomatic, rehabilitative, and palliative care [3, 4], through holistic interventions (incorporate personal and environmental factors) that span the spectrum of the disease. A significant part of the palliative rehabilitation process is the self-empowerment of patients and their families and helping them adapt as the disease progresses. Personal factors, which are defined as the particular background of a person's life and living which are not part of a health condition [5], can be important barriers and/or facilitators to this process, and rehabilitation often aims to enhance facilitating factors whilst underplaying the negative factors to achieve the most optimal functional and social reintegration outcomes. For example, education (for patients and families) is an integral part of MND management, but information provided must be appropriate to the patient's educational level; timing of end-of-life issues depend on a number of factors including coping skills, depression and anxiety, cultural issues, and functional status [6]; technological aids (which can vary considerably in cost) need to suit the patient's socioeconomic status, which impacts on their ability to fund these aids.

The International Classification of Functioning, Disability and Health (ICF) [5] aims to develop a common language for describing the impact of a disease at different levels. 
Within the ICF classification, MND-related impairments (muscle weakness) can limit "activity" (reduced mobility and self care) and "participation" (work, family, and social reintegration). The ICF also acknowledges that environmental factors (physical, social, and attitudinal environment in which people live and conduct their lives) and personal factors (intrinsic influences such as race, gender, and coping styles) interact with all the other constructs within the ICF to affect the person's overall experience of living with their condition. A set of relevant ICF categories in MND would be useful in both clinical and research settings given the rare incidence of MND and diverse and challenging nature of the symptoms. It has been also been highlighted that current outcome measures do not capture the entire spectrum of issues in MND [7]; use of the ICF categories could contribute towards development of appropriate outcome measures for MND. However, at present, personal factors are not classified in the current version of ICF, which represents a significant gap in the overall biopsychosocial view of the condition.

This preliminary study aims to identify the personal factors that are relevant in persons with MND from their perspective, in an Australian cohort.

\section{Methods}

2.1. Participants and Setting. A community-based MND group was recruited through a tertiary MND multidisciplinary clinic that services Victoria, Australia, including metropolitan and rural regions. Selection criteria included diagnosis of MND according to the El Escorial criteria [8] as diagnosed by a neurologist, residence in Victoria, community based (nonhospital inpatient), ability and willingness to give informed consent. Exclusion criteria included severe cognitive issues or dementia and other substantial medical, neurological, or psychiatric disorders. Screening of exclusion criteria was done by a neurologist through consultation of the medical records and liaison with the treating clinicians of the patients. This study was approved by the Melbourne Health and Calvary Healthcare Bethlehem Human Research and Ethics Committees.

All participants $(n=59)$ who met the criteria were contacted by mail and invited to participate in the study. Those who replied affirmatively $(n=44)$ were contacted by telephone by the primary author who explained the study further and organised an interview appointment. Participants were interviewed at a venue of their choice (half were interviewed at home or at hospital and half over the telephone) for one hour with rest breaks.

2.2. Questionnaires. Interviews commenced with an openended self-report questionnaire. Participants were asked, "What are the main problems you face in your everyday life? If possible, can you list and prioritize up to 10 issues that you feel are the most pressing problems you face in everyday life?" Participants were asked to include intrinsic factors that impacted on their experience of these problems, such as their ability to cope. Some who had difficulties with verbal communication chose to write their responses and/or use communication devices.

From the participant responses (from the open-ended questionnaire), all problems relating to personal factors (currently not coded within the ICF) were grouped under "personal factors" and categorized thematically under major headings, which included demographic factors (gender, race, age, and educational status), emotional states (depression, stress, anxiety, and fear), coping strategies and styles (problem-based coping and denial), personality, beliefs (includes self-efficacy, religious beliefs and values, personal and cultural), attitudes (of the patient), and "other" (perceived social support). Reports unrelated to personal factors have not been included in this paper as they are not the primary focus.

Self-administered (patient) questionnaires followed the open-ended questionnaire:

(a) sociodemographic and medical status questionnaire,

(b) amyotrophic lateral sclerosis functional rating scale (ALSFRS) [9] to determine severity of MND. This is a 48-point measure of disability in MND with excellent validity and reliability and can be administered over the phone. It is determined by scoring $0-4$ for each of the twelve domains (speech, salivation, swallowing, handwriting, cutting food and handling utensils, dressing and hygiene, turning in bed and adjusting bed clothes, walking, climbing stairs, dyspnoea, orthopnea, and respiratory insufficiency). A lower score indicates more disability,

(c) depression, anxiety, and stress scale (DASS) [10], a 21-item instrument with acceptable to excellent internal consistency and concurrent validity, consisting of three 7-item self-report scales designed to measure the negative emotional states of depression, anxiety, and stress. Participants rate the extent to which they experienced each state over the past week on a 4point Likert rating scale,

(d) brief COPE [11], a coping inventory, with good reliability and validity, of 14 subscales (active coping, planning, positive reframing, acceptance, humour, religion, using emotional support, using instrumental support, self-distraction, denial, venting, substance use, behavioural disengagement, and selfblame) measuring responses relevant to effective and ineffective coping.

Assistance was provided where necessary by the interviewer and all patient responses were clarified where possible with their caregivers.

2.3. Statistical Analysis. Results were described by mean and standard deviation (SD) for continuous nonskewed data and as frequency (\%) for categorical data. Each identified personal factor was listed once regardless of the frequency of identification either by a single or multiple participant(s) for simplicity. 


\section{Results}

Mean age of participants was 61 years (SD 9.8), and male: female ratio was $3: 2$. Mean time since diagnosis was 3.6 years. Half ( $n=18,41 \%$ ) of the participants had severe disease as classified by ALSFRS (ALSFRS 0-24) (see Table 1). Participants appeared grossly cognitively intact based on simple observation during the interviews. Personal factors identified that were relevant in persons with MND to the experience of their condition are listed in Table 2. Some factors crossed over two categories. For example, "self-esteem" encompassed both a belief (that the patient was worthy) and an emotion (of pride) and is, therefore, listed under both categories. A significant proportion of the participants were depressed $(n=19,43 \%)$, anxious $(18,41 \%)$ and/or stressed $(11,25 \%)$ and problem focused coping strategies were used much more commonly than emotion-focused coping strategies (see Table 3).

\section{Discussion}

This is the first study that has identified personal factors that shape a person with MND's experience of their condition. These factors include demographic factors (gender, race, age, educational status, and socioeconomic status), emotional states (depression, stress, anxiety, and fear), coping strategies and styles (problem-based coping and denial), personality, beliefs (includes self-efficacy, religious beliefs, and personal values), attitudes (of the patient) and "other" (perceived social support). Rates of depression and anxiety were high and a broad range of coping strategies were used although problem-focused coping strategies were preferred. The mean participant age, gender, time since diagnosis, distribution of type, and severity of disease (based on ALSFRS-R) were similar to those reported by others [12]. The participants represented a broad range of disability and disease severity, with demographic and diagnostic characteristics typical of MND.

These findings (of depression, anxiety, and a range of coping strategies) and the identified personal factors are consistent with other reports in MND literature. Rates of depression and anxiety are reported to be $0-44 \%$ and $0-$ $30 \%$, respectively, in persons with MND [13]. This is not surprising given the progressive and fatal nature of their disease. However, it is also generally thought that despite disease progression, most MND patients adjust effectively to their illness and in fact are often perceived to be particularly positive people [14]. The impact of personal factors on the lived experience and QoL of MND should not be underestimated. It has been previously reported that QoL appears to be more dependent on "psychological and existential issues, social support and spirituality" rather than physical factors [15]. These findings were supported by Chiò et al. [16] who found that the main determinants of quality of life in MND were social support, depression, religiosity, and socioeconomic status. More recently, Roach et al. concurred that it was likely that characteristics such as personality, social relationships, and spirituality could be more important for QoL [17] than progression of the disease per se. The importance of coping strategies in the experience of MND is further supported
TABLE 1: Characteristics of motor neurone disease/amyotrophic lateral sclerosis (MND/ALS) participants-demographics and disease features.

\begin{tabular}{|c|c|}
\hline Variable & Average/Frequency \\
\hline Age (mean \pm SD (range) & $61 \pm 9.8(43-80)$ \\
\hline \multicolumn{2}{|l|}{$\operatorname{Sex}[n(\%)]$} \\
\hline Male & $29(65.9)$ \\
\hline Female & $15(34.1)$ \\
\hline \multicolumn{2}{|l|}{ Marital status $(n, \%)$} \\
\hline Married/partner & $34(77.3)$ \\
\hline Divorced/separated/single & $10(22.7)$ \\
\hline \multicolumn{2}{|l|}{ Race $(n, \%)$} \\
\hline Caucasian & $44(100 \%)$ \\
\hline \multicolumn{2}{|l|}{ Living $[n(\%)]$} \\
\hline Alone & $8(18.2)$ \\
\hline Family & $36(82.8)$ \\
\hline \multicolumn{2}{|l|}{ Geographical area } \\
\hline Metropolitan $[n(\%)]$ & $27(61.4)$ \\
\hline $\operatorname{Rural}[n(\%)]$ & $17(38.6)$ \\
\hline \multicolumn{2}{|l|}{$\begin{array}{l}\text { Diagnosis of ALS (El Escorial criteria) }[n \\
(\%)]\end{array}$} \\
\hline Clinically definite ALS & $14(31.8)$ \\
\hline Clinical probable ALS & $17(38.6)$ \\
\hline Probable ALS (Lab Supported) & $5(11.3)$ \\
\hline Possible ALS & $4(9.1)$ \\
\hline Suspected ALS & $4(9.1)$ \\
\hline \multicolumn{2}{|c|}{$\begin{array}{l}\text { Amyotrophic lateral sclerosis functional } \\
\text { rating scale-revised (ALSFRS-R }[n(\%)]\end{array}$} \\
\hline $0-12$ & $3(6.8)$ \\
\hline $13-24$ & $15(34.1)$ \\
\hline $25-36$ & $12(27.3)$ \\
\hline $37-48$ & $14(31.8)$ \\
\hline \multicolumn{2}{|l|}{ Comorbidities $(n, \%)$} \\
\hline Yes & $28(63.6)$ \\
\hline None & $16(36.4)$ \\
\hline$\geq 2$ comorbidities & $14(50.0)$ \\
\hline \multicolumn{2}{|l|}{ Clinical symptoms $(n, \%)$} \\
\hline Fatigue & $34(77.3)$ \\
\hline Pain & $22(50.0)$ \\
\hline Spasticity/cramps/spasms & $32(72.7)$ \\
\hline Emotional lability & $21(47.7)$ \\
\hline Shortness of breath & $8(18)$ \\
\hline
\end{tabular}

by Gallagher and Monroe [18] who surmised that MND is not a static disease but a progressive disorder that required different coping strategies at different stages of the disease. Matuz et al. [14] also found that the best predictors for the severity of depressive symptoms in MND were perceived social support (especially a supportive marital relationship) and coping potential (information seeking and strategies of emotional avoidance behaviour). For example, a combination of confronting and avoiding coping strategies might be 
TABle 2: Personal factors reported by participants with motor neurone disease (MND) which affected their experience of living with MND.

\begin{tabular}{|c|c|}
\hline Personal factors category & Personal factors examples \\
\hline \multirow{5}{*}{ Demographic factors } & Gender \\
\hline & Race \\
\hline & Age \\
\hline & Educational status \\
\hline & Socioeconomic status \\
\hline \multirow{17}{*}{ Emotional states } & Frustration \\
\hline & Depression \\
\hline & Stress \\
\hline & Anxiety \\
\hline & Fear \\
\hline & Worry \\
\hline & Degrading \\
\hline & Grumpy \\
\hline & Loss of confidence \\
\hline & Anger \\
\hline & Self-esteem \\
\hline & Embarrassment \\
\hline & Hope (both hopeful and hopeless) \\
\hline & Guilt \\
\hline & Grief \\
\hline & Loss \\
\hline & Gratitude \\
\hline \multirow{10}{*}{ Coping strategies and styles } & Problem solving \\
\hline & Search for information \\
\hline & Planning \\
\hline & Positivity \\
\hline & Acceptance \\
\hline & Humour \\
\hline & Religion \\
\hline & Using support \\
\hline & Denial \\
\hline & Avoidance \\
\hline \multirow{2}{*}{ Personality } & Stubborn \\
\hline & Easy-going \\
\hline \multirow{2}{*}{ Beliefs } & Religious beliefs \\
\hline & Self-esteem \\
\hline \multirow{4}{*}{ Attitudes (of the patient) } & $\begin{array}{l}\text { Grateful attitude (towards family } \\
\text { and health professionals) }\end{array}$ \\
\hline & Fighting attitude \\
\hline & Attitude towards assisted suicide \\
\hline & Being organised \\
\hline "Other" & Perceived support \\
\hline
\end{tabular}

useful for MND patients, because search of information and support may help them to initiate actions that ensure optimal future care [14]. On the other hand, emotional avoidance behaviour (e.g., choosing isolation or denial) could protect
TABLE 3: Results of depression, anxiety, and stress scale (DASS) and brief COPE.

\begin{tabular}{|c|c|c|}
\hline DASS & {$[n,(\%)]$} & \\
\hline \multicolumn{3}{|l|}{ DASS Depression } \\
\hline Normal & $25(56.8 \%)$ & \\
\hline Mild & $9(20.5)$ & \\
\hline Moderate & $4(9.1 \%)$ & \\
\hline Severe & $3(6.8 \%)$ & \\
\hline Extreme & $3(6.8 \%)$ & \\
\hline \multicolumn{3}{|l|}{ DASS Anxiety } \\
\hline Normal & $26(59.1 \%)$ & \\
\hline Mild & $6(13.6 \%)$ & \\
\hline Moderate & $4(9.1 \%)$ & \\
\hline Severe & $4(9.1 \%)$ & \\
\hline Extreme & $4(9.1 \%)$ & \\
\hline \multicolumn{3}{|l|}{ DASS Stress } \\
\hline Normal & $33(75.0 \%)$ & \\
\hline Mild & $6(13.6 \%)$ & \\
\hline Moderate & $2(4.5 \%)$ & \\
\hline Severe & $3(6.8 \%)$ & \\
\hline Extreme & 0 & \\
\hline Brief COPE variables & Mean (SD) & Range \\
\hline \multicolumn{3}{|l|}{ Problem focused coping strategies } \\
\hline Active coping $(2-8)$ & $6.3(1.6)$ & $2-8$ \\
\hline Planning (2-8) & $6.2(1.7)$ & $2-8$ \\
\hline Positive reframing (2-8) & $6.0(1.8)$ & $2-8$ \\
\hline Acceptance $(2-8)$ & $7.4(1.1)$ & $2-8$ \\
\hline Humour (2-8) & $5.0(2.4)$ & $2-8$ \\
\hline Religion (2-8) & $4.0(2.3)$ & $2-8$ \\
\hline Using emotional support (2-8) & $6.3(1.5)$ & $3-8$ \\
\hline Using instrumental support (2-8) & $5.7(1.7)$ & $2-8$ \\
\hline \multicolumn{3}{|l|}{ Emotion-focused coping strategies } \\
\hline Self-distraction $(2-8)$ & $5.7(2.0)$ & $2-8$ \\
\hline Denial $(2-8)$ & $2.9(1.4)$ & $2-8$ \\
\hline Venting (2-8) & $3.6(1.6)$ & $2-8$ \\
\hline Substance use (2-8) & $2.7(1.5)$ & $2-8$ \\
\hline Behavioural disengagement (2-8) & $2.8(1.4)$ & $2-7$ \\
\hline Self-blame (2-8) & $2.7(1.0)$ & $2-6$ \\
\hline
\end{tabular}

them from psychological distress and despair [19]. However, as the disease progresses, avoidance is no longer an adaptive strategy, as it prevents patients from taking appropriate measure to cope further with the illness [14].

Personality appears to be another personal factor that plays a significant role in the experience of MND. It has been found that MND patients $(n=31)$ who scored higher on the agreeableness personality dimension had higher QoL initially, but the reduction of QoL over 12 months was significantly steeper than in patients who scored lower on agreeableness, suggesting that being less agreeable might serve as a protective factor with respect to QoL [20]. Nelson et al. [21] reported that personality traits such as optimism, flexibility, and humor were important in coping. As for 
beliefs, it has been reported that the belief that fate controls one's health and a person's belief in "powerful others" such as doctors changes with disease progression in MND [22]. Interestingly, no cultural beliefs were mentioned in this cohort, possibly because of the homogeneity in race (100\% Caucasian) in this cohort, but religious beliefs were frequently mentioned, consistent with the high proportion (64\%) of Christianity practiced in Australia [23] and with previous reports that religion is one of the most important coping mechanisms in a fatal disease such as MND [24]. Finally, other studies have reported that the most important personal values in MND patients were benevolence, selfdirection, and universalism [25]. These values were not specifically explored in this cohort.

Under the UK Department of Health's National Service Framework for Long-term Neurological Conditions [26], MND is a "progressive condition" with a rapid deteriorating course. Multiple sclerosis is another long-term progressive neurological condition but with a more "intermittent," slowly "progressive" or "stable" nature. Comparison of relevant personal factors in MND with other "long-term neurological conditions" is challenging as it differs from other conditions in that there is constant deterioration and, therefore, ongoing "change and adaptation" [27]. It is also unique in that given the limited life span, changes in personal factors can be studied through the entire spectrum of the disease, as described above. There are few other reports relating to personal factors in other long-term neurological conditions. In identifying the ICF core set for multiple sclerosis, Khan and Pallant [28] suggested ten categories which included socioeconomic status, coping ability, attitudes and patient beliefs, self-efficacy, dependence on others, mood and affect, heat intolerance, fatigue, personality and temperament, and patient attitude towards the biopsychosocial impact of multiple sclerosis. Many of these are comparable with this MND cohort. Other reports have shown that in both MND and multiple sclerosis, psychological adaptation to deteriorating function is an important factor in perceived QoL and emotional wellbeing [29]. The impact of personal factors on participation in the rehabilitative process in other neurological conditions has also been emphasized-a recent study showed that rehabilitation professionals attempting to engage people with multiple sclerosis in a physical activity programme needed to consider adopting an individualised approach to barrier management which takes into account personal beliefs and perceptions regarding physical activity engagement [30]. Hence, despite some of the unique features of MND, many of the findings in this study are likely to be relevant to other neurological conditions.

MND takes its toll on the patient and family especially as the disease progresses and loss of independence occurs. Understanding the personal factors involved helps with the palliative rehabilitation process. As part of this process, advice with regards to adequate coping strategies and provision of an adequate amount of disease- and support-related information at any one time and encouraging patients to seek social support [14] is crucial. Hence, referrals to support groups and counselling and education of patients and their families (often their caregivers) are important. Subgroups of patients who are more likely to adapt poorly to a new diagnosis of MND can also be identified early with explorative interviews that specifically target coping, depression, anxiety, social withdrawal, and quality of life [31]. Targeted earlier intervention can be provided for this subgroup. Frank discussions facilitate understanding of the disease and improve coping skills. Referrals to the local MND associations are also recommended as these provide patients and families with ongoing support, resources and equipment needs. Psychotherapy should also be considered to assist with coping strategies [14] and antidepressants may be used. Anxiety is difficult to measure due to physical confounding symptoms such as shortness of breath, muscle cramps, and restlessness. Anxiety can be treated with psychotherapy and training in relaxation and breathing techniques as well as participation in support groups. With good support, mental health and quality of life can remain stable despite deteriorating physical health [32]. In addition, an often-neglected part of rehabilitation in MND is support for continuation of work [33]. Understanding personal factors can help target the subgroup of MND patients who wish to continue workit has been found that intrinsic reasons (motivation resulting from a person's interest in and enjoyment of the work), followed by age, disability severity, and accessibility of travel [34] are the strongest predictors for this group.

The limitations in this study include cross-sectional survey (no longitudinal information), highly selective cohort (all already receiving tertiary multidisciplinary care, and willing research participants). Interviews were challenging given the fragile emotional and physical status of the participants. Self-reported information was used and validated as best with caregiver and medical records. The cohort covers a wide geographical population in Victoria and is representative of the wider sample of pwMND.

MND is a devastating illness for patients and families. Palliative care and rehabilitation has much to offer this population. For improved consensus of care and communication amongst treating clinicians, the framework of ICF should be explored in this population and further expanded to take into consideration individual personal factors which impact significantly upon the experience of illness and the rehabilitation process. This preliminary study identifies intrinsic factors reported by patients with MND and may be the first step in the development of personal factors within the ICF classification.

\section{Acknowledgments}

The authors would like to thank their participants with MND without whom this study would not have been possible. They would also like to thank Associate Professor Paul Talman for his assistance in participant recruitment.

\section{References}

[1] L. Forsgren, B. G. L. Almay, G. Holmgren, and S. Wall, "Epidemiology of motor neuron disease in Northern Sweden," Acta Neurologica Scandinavica, vol. 68, no. 1, pp. 20-29, 1983. 
[2] L. M. Klein and D. A. Forshew, "The economic impact of ALS," Neurology, vol. 47, no. 4, pp. S126-S129, 1996.

[3] R. G. Miller, C. E. Jackson, E. J. Kasarskis et al., "Practice Parameter update: the care of the patient with amyotrophic lateral sclerosis: multidisciplinary care, symptom management, and cognitive/behavioral impairment (an evidence-based review): report of the Quality Standards Subcommittee of the American Academy of Neurology," Neurology, vol. 73, no. 15, pp. 1227-1233, 2009.

[4] P. M. Andersen, G. D. Borasio, R. Dengler et al., "Good practice in the management of amyotrophic lateral sclerosis: clinical guidelines. An evidence-based review with good practice points. EALSC Working Group," Amyotrophic Lateral Sclerosis, vol. 8, no. 4, pp. 195-213, 2007.

[5] World Health Organization, "International Classification of Functioning, Disability, and Health (ICF)," Geneva, Switzerland, 2001.

[6] H. Mitsumoto, M. Bromberg, W. Johnston et al., "Promoting excellence in end-of-life care in ALS," Amyotrophic Lateral Sclerosis and Other Motor Neuron Disorders, vol. 6, no. 3, pp. 145-154, 2005.

[7] L. Ng, F. Khan, and S. Mathers, "Multidisciplinary care for adults with amyotrophic lateral sclerosis or motor neuron disease," Cochrane Database of Systematic Reviews, no. 4, Article ID CD007425, 2009.

[8] B. R. Brooks, R. G. Miller, M. Swash, and T. L. Munsat, "El Escorial revisited: revised criteria for the diagnosis of amyotrophic lateral sclerosis," Amyotrophic Lateral Sclerosis and Other Motor Neuron Disorders, vol. 1, no. 5, pp. 293-299, 2000.

[9] P. Kaufmann, G. Levy, J. Montes et al., "Excellent interrater, intra-rater, and telephone-administered reliability of the ALSFRS-R in a multicenter clinical trial," Amyotrophic Lateral Sclerosis, vol. 8, no. 1, pp. 42-46, 2007.

[10] S. H. Lovibond and P. F. Lovibond, Manual for the Depression Anxiety Stress Scales, Psychology Found of Australia, Sydney, Australia, 1995.

[11] C. S. Carver, "You want to measure coping but your protocol's too long: consider the brief COPE," International Journal of Behavioral Medicine, vol. 4, no. 1, pp. 92-100, 1997.

[12] L. J. Haverkamp, V. Appel, and S. H. Appel, "Natural history of amyotrophic lateral sclerosis in a database population. Validation of a scoring system and a model for survival prediction," Brain, vol. 118, no. 3, pp. 707-719, 1995.

[13] A. Kurt, F. Nijboer, T. Matuz, and A. Kübler, "Depression and anxiety in individuals with amyotrophic lateral sclerosis: epidemiology and management," CNS Drugs, vol. 21, no. 4, pp. 279-291, 2007.

[14] T. Matuz, N. Birbaumer, M. Hautzinger, and A. Kübler, "Coping with amyotrophic lateral sclerosis: an integrative view," Journal of Neurology, Neurosurgery and Psychiatry, vol. 81, no. 8, pp. 893-898, 2010.

[15] Z. Simmons, B. A. Bremer, R. A. Robbins, S. M. Walsh, and S. Fischer, "Quality of life in ALS depends on factors other than strength and physical function," Neurology, vol. 55, no. 3, pp. 388-392, 2000.

[16] A. Chiò, A. Gauthier, A. Montuschi et al., "A cross sectional study on determinants of qualify of life in ALS," Journal of Neurology, Neurosurgery and Psychiatry, vol. 75, no. 11, pp. 1597-1601, 2004.

[17] A. R. Roach, A. J. Averill, S. C. Segerstrom, and E. J. Kasarskis, "The dynamics of quality of life in ALS patients and caregivers," Annals of Behavioral Medicine, vol. 37, no. 2, pp. 197206, 2009.
[18] D. Gallagher and B. Monroe, "Psychosocial care," in Palliative Care in Amyotrophic Lateral Sclerosis: From Diagnosis to Bereavement, D. Oliver, G. D. Borasio, and D. Walsh, Eds., pp. 143-168, Oxford University Press, Oxford, UK, 2nd edition, 2006.

[19] L. Locock and J. B. Brown, "'All in the same boat'? Patient and carer attitudes to peer support and social comparison in Motor Neurone Disease (MND)," Social Science and Medicine, vol. 71, no. 8, pp. 1498-1505, 2010.

[20] H. Krampe, C. Bartels, D. Victorson et al., "The influence of personality factors on disease progression and healthrelated quality of life in people with ALS," Amyotrophic Lateral Sclerosis, vol. 9, no. 2, pp. 99-107, 2008.

[21] N. D. Nelson, M. Trail, J. N. Van, S. H. Appel, and E. C. Lai, "Quality of life in patients with amyotrophic lateral sclerosis: perceptions, coping resources, and illness characteristics," Journal of Palliative Medicine, vol. 6, no. 3, pp. 417-424, 2003.

[22] L. H. Goldstein, L. Atkins, and P. N. Leigh, "Health-related locus of control: does it change in motor neurone disease (MND)?" Amyotrophic Lateral Sclerosis and Other Motor Neuron Disorders, vol. 4, no. 1, pp. 27-30, 2003.

[23] Australian Bureau of Statistics, "Migration 2006 Census," 2007, http://www.ausstats.abs.gov.au/ausstats/subscriber.nsf/ 0/E0A79B147EA8E0B5CA2572AC001813E8/\$File/34120_200506.pdf.

[24] M. Hecht, T. Hillemacher, E. Gräsel et al., "Subjective experience and coping in ALS," Amyotrophic Lateral Sclerosis and Other Motor Neuron Disorders, vol. 3, no. 4, pp. 225-232, 2002.

[25] M. J. Fegg, M. Wasner, C. Neudert, and G. D. Borasio, "Personal values and individual quality of life in palliative care patients," Journal of Pain and Symptom Management, vol. 30, no. 2, pp. 154-159, 2005.

[26] Department of Health, "The National Service Framework (NSF) for Long-term conditions," London, UK, 2005.

[27] S. J. King, M. M. Duke, and B. A. O'Connor, "Living with amyotrophic lateral sclerosis/motor neurone disease (ALS/MND): decision-making about 'ongoing change and adaptation'”, Journal of Clinical Nursing, vol. 18, no. 5, pp. 745$754,2009$.

[28] F. Khan and J. F. Pallant, "Use of the International Classification of Functioning, Disability and Health (ICF) to identify preliminary comprehensive and brief core sets for multiple sclerosis," Disability and Rehabilitation, vol. 29, no. 3, pp. 205213, 2007.

[29] L. J. O’Doherty, A. Hickey, and O. Hardiman, "Measuring life quality, physical function and psychological well-being in neurological illness," Amyotrophic Lateral Sclerosis, vol. 11, no. 5, pp. 461-468, 2010.

[30] N. M. Kayes, K. M. McPherson, D. Taylor, P. J. Schlüter, and G. S. Kolt, "Facilitators and barriers to engagement in physical activity for people with multiple sclerosis: a qualitative investigation," Disability and Rehabilitation, vol. 33, no. 8, pp. 625-642, 2011.

[31] H. Hugel, N. Pih, C. P. Dougan, S. Rigby, and C. A. Young, "Identifying poor adaptation to a new diagnosis of motor neuron disease: a pilot study into the value of an early patientled interview," Amyotrophic Lateral Sclerosis, vol. 11, no. 1-2, pp. 104-109, 2010.

[32] I. J. M. De Droot, M. W. M. Post, T. van Heuveln, L. H. van den Berg, and E. Lindeman, "Cross-sectional and longitudinal correlations between disease progression and different healthrelated quality of life domains in persons with amyotrophic lateral sclerosis," Amyotrophic Lateral Sclerosis, vol. 8, no. 6, pp. 356-361, 2007. 
[33] L. Ng, P. Talman, and F. Khan, "Motor neurone disease: disability profile and service needs in an Australian cohort," International Journal of Rehabilitation Research, vol. 34, no. 2, pp. 151-159, 2011.

[34] J. D. Westaby, A. Versenyi, and R. C. Hausmann, "Intentions to work during terminal illness: an exploratory study of antecedent conditions," Journal of Applied Psychology, vol. 90, no. 6, pp. 1297-1305, 2005. 


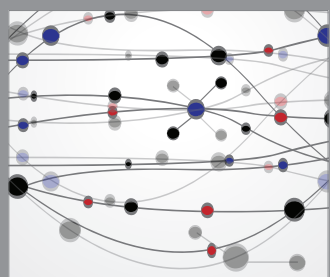

The Scientific World Journal
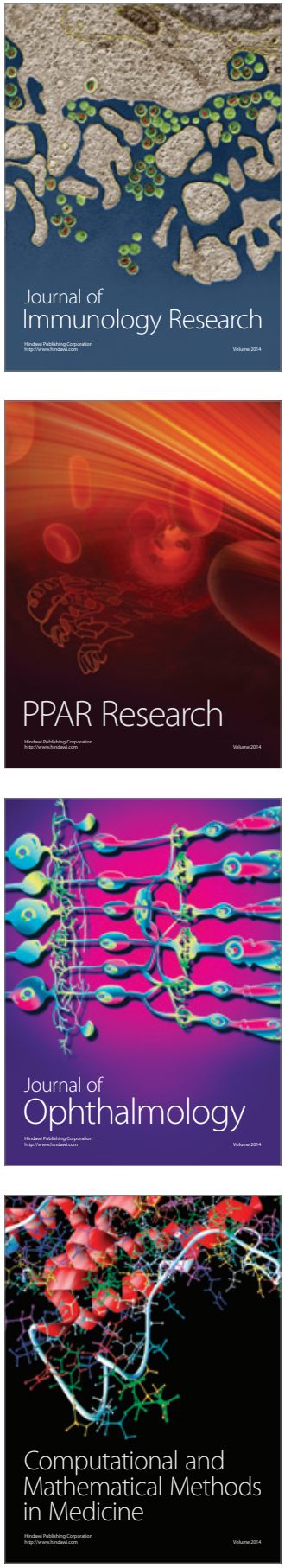

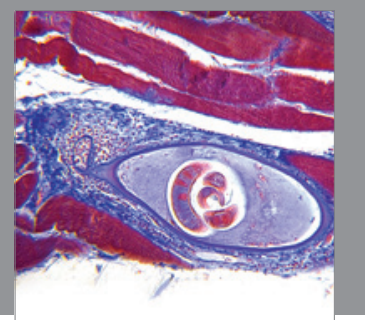

Gastroenterology

Research and Practice
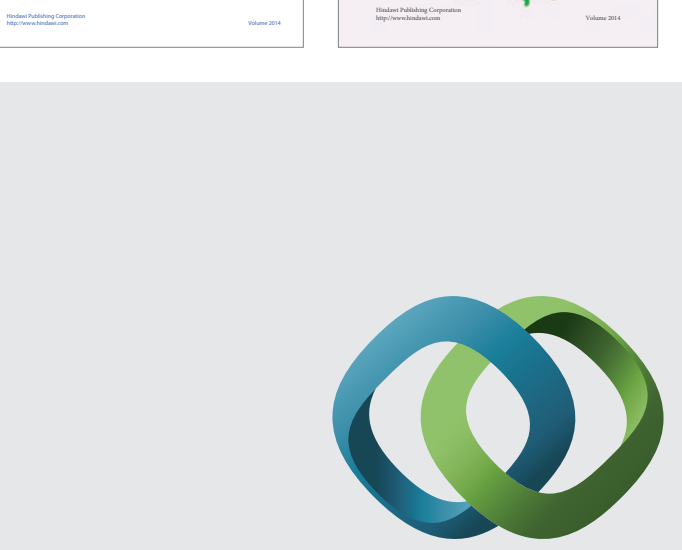

\section{Hindawi}

Submit your manuscripts at

http://www.hindawi.com
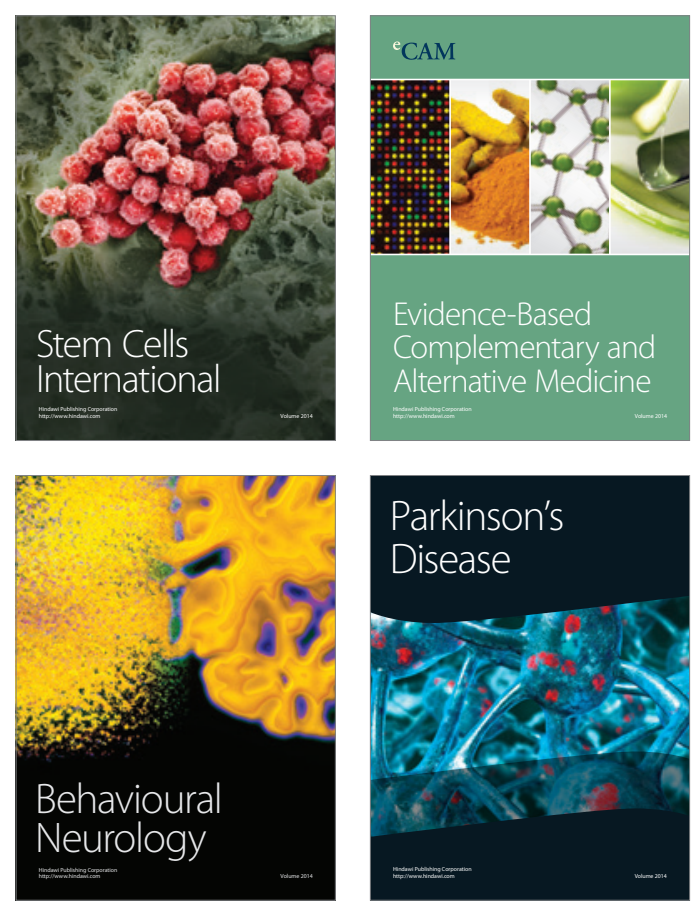

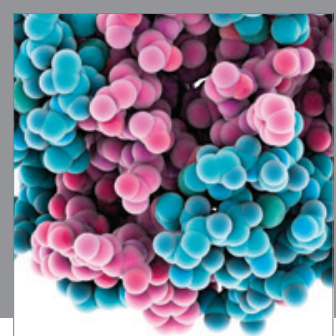

Journal of
Diabetes Research

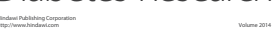

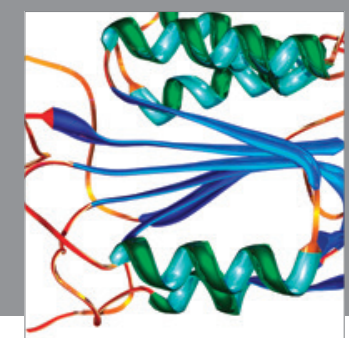

Disease Markers
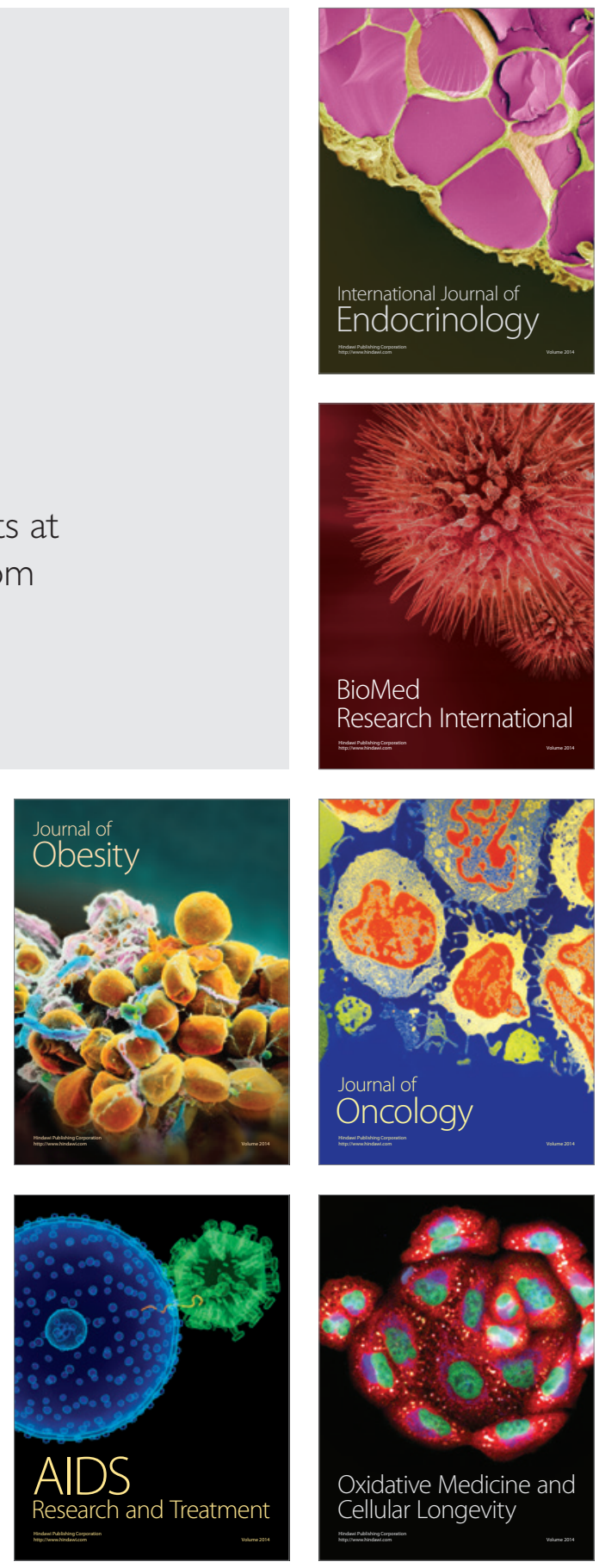